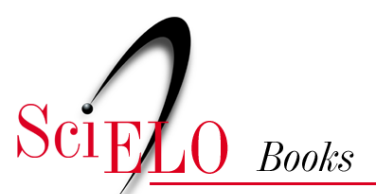

\title{
4. Atuação da Abrasco em relação ao ensino de pós-graduação na área de $\underline{\text { saúde coletiva }}$
}

\author{
Maria Cecília de Souza Minayo
}

\section{SciELO Books / SciELO Livros / SciELO Libros}

MINAYO, M. C. S. Atuação da Abrasco em relação ao ensino de pós-graduação na área de saúde coletiva. In: LIMA, N. T., and SANTANA, J. P., ed s. Saúde coletiva como compromisso: a trajetória da Abrasco [online]. Rio de Janeiro: Editora FIOCRUZ; Abrasco, 2006, pp. 117-144. ISBN: 978-65-5708-156-3. https://doi.org/10.7476/9786557081563.0005.

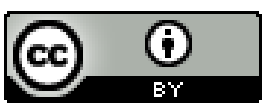

All the contents of this work, except where otherwise noted, is licensed under a Creative Commons Attribution 4.0 International license.

Todo o conteúdo deste trabalho, exceto quando houver ressalva, é publicado sob a licença Creative Commons Atribição 4.0.

Todo el contenido de esta obra, excepto donde se indique lo contrario, está bajo licencia de la licencia $\underline{\text { Creative }}$ Commons Reconocimento 4.0. 


\section{Atuação da Abrasco em Relação ao Ensino de Pós-GraduaÇão na Área de Saúde Coletiva}

Maria Cecília de Souza Minayo

A pós-graduação em Saúde Coletiva, no estrito e no lato senso, é o coração da Abrasco, na medida em que ela se constitui como uma associação científica e porta o termo 'pós-graduação' na composição do próprio nome. Por essa razão, este texto trata da instituição na perspectiva de sua função precípua, a formação de recursos humanos, função a partir da qual ela tem uma fala qualificada nas políticas, na gestão, na atenção à saúde e nas representações institucionais no país e internacionalmente.

Desde o primeiro momento de existência da associação, as questões de ensino e pesquisa estiveram presentes em sua práxis, embora a priorização de determinados aspectos venha ocorrendo em momentos diferenciados. Num primeiro instante, sua ênfase recaiu mais sobre o nível de pós-graduação lato sensu; num segundo, predominou seu engajamento nas questões de políticas de saúde e, nos últimos anos, na relevância dada à pós-graduação stricto sensu (Belisário, 2002).

A Associação Brasileira de Pós-Graduação em Saúde Coletiva, em diversos momentos da história, realizou diagnósticos sobre ensino e pesquisa nas várias modalidades de pós-graduação, bem como em áreas específicas, como nas ciências sociais, no planejamento e administração e na epidemiologia, como destacam Nunes \& Costa (1997). A memória da instituição mostra também a realização de uma série de encontros, oficinas e seminários setoriais, objetivando a articulação dos cursos de Saúde Pública stricto sensu, de especialização e de residência em medicina preventiva e social, além dos congressos. 
Embora nenhum nível de ensino, inclusive o de graduação, tenha ficado esquecido em toda a trajetória da Abrasco, na década de 90 se observou um investimento maior na perspectiva de formação de recursos humanos nos níveis de mestrado e doutorado. Da metade da década de 80 até o início dos anos 90 - correspondendo ao período da VIII Conferência, da Constituição de 1988, da elaboração da Lei Orgânica da Saúde e do início da implementação do Sistema Único de Saúde, o SUS -, a associação enfatizou mais seu papel na formulação das políticas de saúde e na assessoria à sua implementação e, a partir de 1992, retornou ao seu papel precípuo no âmbito da formação de recursos humanos, agora dando ênfase ao nível de mestrado e de doutorado. Esta última é uma etapa de reestruturação e reafirmação pressionadas por transformações pelas quais o setor saúde vinha passando, o que exigia um novo perfil profissional na área da Saúde Coletiva. Tal momento também foi marcado por uma intensificação da divulgação da produção científica da entidade, com investimento numa livraria que passou a atender a leitores, professores e estudantes de todo o país, além do incremento dos veículos de divulgação e de publicações próprias, com a criação de duas revistas especializadas.

Sem ter um papel regulador e normativo que cabe às instituições e ao Ministério da Educação por meio da Coordenação de Aperfeiçoamento de Pessoal de Nível Superior (Capes), a associação congrega e apóia professores, pesquisadores e coordenadores, orienta a filosofia dos cursos, divulga conhecimentos e sistematiza a situação da área no nível de formação pós-graduada. Nesse particular, ela tem uma atividade semelhante a todas as outras instituições científicas brasileiras, muitas delas surgidas na mesma década de 70 , em pleno regime militar, quando a organização da sociedade civil deu passos importantes, dentre outros motivos, criando espaços de liberdade de expressão e de interesses. A Abrasco também atua na relação com as instituições de avaliação e fomento, indicando nomes para compor comissões e mediando demandas dos coordenadores de cursos e também de pesquisadores, visando garantir a identidade e a unidade orgânica da área. Esse foi o caso recente do documento "Em nome da Saúde Pública/ Saúde Coletiva", levado a público em dezembro de 2005. Nessa ocasião, a Abrasco interveio numa comissão da Capes, do Conselho Nacional de Desenvolvimento Científico e Tecnológico/Ministério da Ciência e Tecnologia (CNPq/MCT) e da Financiadora de Estudos e Projetos (Finep/ MCT), que haviam apresentado uma nova tabela de áreas de conhecimento, desconhecendo a racionale do campo da Saúde Coletiva (Abrasco, 2005).

Este texto dará ênfase ao papel da Abrasco em relação à pósgraduação stricto sensu, mas tratará brevemente de sua importância na 
trajetória da formação de recursos humanos para a residência médica em medicina preventiva e social e em especialização em Saúde Pública/Coletiva. Não existe aqui um julgamento de valor sobre os três níveis. Apenas é preciso dizer que as avaliações sistemáticas vêm ocorrendo somente no âmbito da pós-graduação stricto sensu, de tal forma que, para fazer uma análise detalhada e atualizada do seu papel no nível lato sensu, seria preciso realizar uma pesquisa de campo sobre o que vem acontecendo do ponto de vista quantitativo e qualitativo. Infelizmente, essa importante tarefa não foi realizada.

IMPORTÂNCIA DA ABRASCO PARA A ForMAÇÃO DA PÓS-

\section{GradUAÇÃo LATO SENSU. ESPECIALIZAÇÃO E RESIDÊNCIA EM} MEDICINA PREVENTIVA

Os dados mencionados aqui são uma compilação das informações de Belisário (2002) com base na pesquisa realizada para sua tese de doutorado, em que traça, minuciosamente, a história da Abrasco. No capítulo 6, a autora discorre sobre o papel da associação na formação de recursos humanos. Pode-se observar, pela documentação utilizada por Belisário, que existe pouco material para se fazer uma avaliação aprofundada das relações dessa entidade com os cursos de pós-graduação lato sensu. Como ela lembra muito bem, os registros existentes constituem material muito simples de memória de encontros e reuniões, realizados com objetivos específicos, como se verá a seguir. Significa que não houve até hoje, na Abrasco, nem uma pesquisa avaliativa que pudesse dimensionar a magnitude dessas iniciativas, nem estudos qualitativos que evidenciassem, com mais rigor, o significado delas para a área, embora alguns presidentes da instituição, entrevistados por Belisário, lamentem não terem tido condições objetivas para fazer isso.

Apesar dessa escassez de documentos históricos e científicos, os encontros permitem ver os movimentos internos e externos que marcam a evolução e a involução do papel da Abrasco na formulação dessa modalidade de formação. Todos os registros ressaltam que o maior investimento da associação nesse sentido ocorreu do final dos anos 70 até meados dos anos 80. Sua presença, então, se fez sentir nas residências médicas e nos cursos de especialização. No início dos anos 80 , vários fóruns, seminários, encontros e reuniões nesse nível de pós-graduação foram realizados.

Os objetivos de tais encontros eram, em geral, a realização de diagnóstico da situação do ensino e da pesquisa nessas modalidades de 
pós-graduação e nas áreas específicas de conhecimento; a avaliação da inter-relação dos programas com os serviços de saúde; o levantamento de seus principais problemas e dificuldades; a promoção do conhecimento; o efetivo intercâmbio entre os docentes, pesquisadores, alunos e pessoal de serviço de áreas afins; e a definição de estratégias comuns de trabalho. No caso dos cursos de especialização e de residência, os seminários e reuniões concentravam-se na questão do ensino profissional, no sentido de produzir capacitação e formar massa crítica na área.

No final dos anos 70 e início dos anos 80, o mercado de trabalho tanto para os que faziam residência em medicina preventiva e social como para os especialistas em Saúde Pública - apresentava forte tendência expansionista, em virtude do interesse do Instituto Nacional de Assistência Médica da Previdência Social (Inamps) de contratar esses profissionais. Nessa conjuntura, esse tipo de recursos humanos tornava-se vital para a operação e o desenvolvimento de novas atividades, preconizadas no planejamento do setor saúde, principalmente no âmbito da Previdência Social.

Estudo realizado sobre essa época (Belisário, 2002) demonstra que, em 1979, o Inamps programava absorver 1.800 profissionais da área de Saúde Pública e Medicina Social, colocando como tarefa prioritária, para a primeira diretoria da Abrasco e seus afiliados, apresentar uma proposta que mostrasse a 'inadiável' necessidade de incorporação desses profissionais mediante concurso público até 1983. Infelizmente, esse propósito não foi alcançado.

À medida que o sistema Inamps foi se desfazendo e todas as suas atividades se integrando ao Ministério da Saúde, houve uma queda na demanda por profissionais especialistas. A residência em medicina preventiva progressivamente perdeu espaço e status, perda essa advinda, dentre outros fatores, do fato de ela se constituir numa modalidade longa de formação, da retração do mercado de trabalho e também das dificuldades de compatibilização de uma formação interdisciplinar com uma carreira tipicamente médica. Em geral, as residências em seu formato tradicional ocorriam no interior da formação em medicina stricto sensu, e a área de Saúde Coletiva, intrinsecamente interdisciplinar, até hoje não conseguiu legitimar o reconhecimento de sua residência multiprofissional pelo Ministério da Educação.

A despeito de alguns programas multiprofissionais continuarem a trabalhar com saídas alternativas, oferecendo o título de especialistas a profissionais não médicos que cursam a residência em Saúde Pública/ Coletiva, essa é uma questão que se mantém como desafio para a associação. Como fruto das tentativas da Abrasco, o máximo que se 
conseguiu foi a construção e a publicação da Resolução 16/1981 da Comissão Nacional de Residência Médica (CNRM), que delimitou o espaço e definiu os objetivos dessa modalidade de formação para os médicos que cursavam residência em medicina preventiva e social.

A mudança de perspectiva de enfoque da própria associação vai progressivamente indicar um certo abandono da formação dos especialistas em Saúde Coletiva/Saúde Pública, levando a um declínio da preocupação com os cursos de pós-graduação lato sensu. Diferentemente do ímpeto dos primeiros anos, os cursos de pós-graduação lato sensu ficaram um pouco à margem das discussões da associação, coincidindo com o desinteresse dos profissionais médicos pela formação básica em Saúde Pública. Ganharam importância os cursos específicos em subáreas de conhecimento, o que mostra uma tendência de especialização disciplinar - mesmo assim, ao longo do tempo, muitos cursos oferecidos foram se esvaziando. É bem verdade que alguns, como o de saúde do trabalhador, de preparação de profissionais para lidar com a saúde dos idosos e sobre saúde mental (no âmbito da Saúde Coletiva), continuaram pujantes e com uma demanda expressiva. Muitas dessas iniciativas passaram, ao longo do tempo, a ser organicamente articuladas à formação de pós-graduação stricto sensu. No terceiro volume da série Ensino da Saúde Pública, Medicina Preventiva e Social no Brasil, publicado em 1983 (apud Belisário, 2002), a Abrasco introduziu a discussão de temas específicos por meio de grupos de trabalho constituídos por especialistas, produzindo uma série de informes técnicos que apontavam essa tendência de especialização por subáreas como nova estratégia na abordagem das questões relativas ao ensino e à pesquisa em Saúde Coletiva.

Ainda em 1983, a Abrasco promoveu, junto com a Associação Brasileira de Educação Médica (Abem), um grande fórum sobre o ensino de Saúde Pública/Coletiva na graduação. Reuniu docentes de medicina preventiva e social das 76 escolas médicas existentes no país, naquela época, para: a) discutir um plano de ação para o ensino na graduação com base na transformação dos conceitos e práticas de serviços de saúde e do ensino médico; b) rever a evolução ocorrida no movimento brasileiro de medicina preventiva; e c) debater as tendências recentes do mercado de trabalho e proposições estratégicas para um programa nacional de desenvolvimento do ensino da medicina preventiva e social. No fórum, fez-se um breve diagnóstico da situação do ensino na graduação. Dentre as recomendações, foi sugerido que a Abrasco estabelecesse um núcleo de reflexão sobre a graduação. No entanto, tal objetivo não foi alcançado até o momento presente. 
Não é possível delongar a reflexão sobre o papel da Abrasco na pós-graduação lato sensu e, muito menos, em relação à graduação. Não que esses níveis de formação devam ser considerados menores ou menos importantes, mas porque faltam documentos ou pesquisas empíricas que dêem o devido embasamento. Pode-se depreender, seguindo o fio que tece o conjunto das atividades da associação em relação à formação de recursos humanos, algumas tendências: a) maior exigência do mercado de trabalho do setor, puxando para cima as exigências de formação para o nível stricto sensu, o que redundou, do ano 2000 em diante, nos mestrados profissionais; b) urgência e relevância de produzir outros tipos de formação ou mais rápidas, ou mais intensivas ou pela modalidade de ensino a distância, de modo a atender a todo o processo de descentralização inaugurado pelo Sistema Único de Saúde (SUS), a partir da Constituição de 1988, e depois pela Lei Orgânica da Saúde, de 1990. Esse movimento de mudanças se tornou explícito na década de 90 . Ele não acabou com nada do que vinha ocorrendo, mas rearrumou as demandas do setor em outro patamar ou em outras direções.

\section{IMPORTÂNCIA DA Abrasco Para a Pós-GraduaÇão STRICTO SENSU}

A seguir se busca descrever e analisar o importante papel da Abrasco na construção da pós-graduação stricto sensu da área de Saúde Coletiva/Pública/Medicina Preventiva e Social/Medicina Social. E, também, mapear os caminhos de possibilidades ainda a serem construídas. É dada ênfase à pesquisa avaliativa realizada pela instituição em 1995-1996, como um momento de inflexão na gestão da associação com referência a essa importante construção coletiva.

Desde o seu nascimento, a Abrasco realizou ações para conhecer e orientar a política de formação e de pesquisa na pós-graduação stricto sensu. Os documentos existentes mostram que, em nome da associação, Magaldi \& Cordeiro (1983) fizeram um primeiro levantamento que cobriu os seis primeiros programas, dois com mestrado e doutorado e quatro só com mestrado, existentes em 1981. Em 1982, Marsiglia \& Rossi (1983) sistematizaram, também no âmbito da Abrasco, vários aspectos relativos à pesquisa, ao ensino e ao corpo docente dos cursos vigentes. Igualmente, no ano seguinte Temporão \& Rivera (1983) publicaram uma caracterização dos docentes das disciplinas de planejamento e administração em saúde. Posteriormente, Cohn \& Nunes (1988) fizeram uma análise sobre as características dos oito programas existentes na época. Todos esses trabalhos 
e seus resultados estão citados em Nunes \& Costa (1997), em artigo que apresenta as conclusões de uma pesquisa referente aos cursos de mestrado e doutorado - um estudo sobre as disciplinas básicas. Cita-se ainda uma investigação sobre pesquisa em epidemiologia no Brasil, realizada por Guimarães, Lourenço \& Cosac (2002), encomendada pela Comissão de Epidemiologia da Abrasco e publicada na série Estudos em Saúde Coletiva, número 216. Além desses estudos sistemáticos, em todos os congressos da associação, ao longo do tempo, os coordenadores dos programas vêm se reunindo, socializando problemas, propostas e soluções.

$\mathrm{O}$ investimento mais aprofundado e abrangente destinado aos programas de pós-graduação, liderado pela Abrasco, ocorreu em 19951996. A associação reuniu alguns de seus melhores pensadores, propondolhes uma pesquisa avaliativa sobre os seguintes aspectos: a) construção dos programas; b) conteúdo da formação; c) perfil da demanda pelos cursos; d) perfil dos egressos; e) especificidade da produção científica; f) difusão científica. Tal iniciativa, corroborada em todos os momentos por consultores externos, deveu-se a vários fatores, todos eles visando contribuir para o aprimoramento do pensamento científico da área. A pesquisa avaliativa foi concebida pela diretoria da Abrasco dos anos 1992-1994, organizada e coordenada pela gestão seguinte (Minayo, 1997; Minayo \& Costa, 1998) e financiada em parte pelo Conselho Nacional de Desenvolvimento Científico e Tecnológico (CNPq) e pela Coordenação de Aperfeiçoamento de Pessoal de Nível Superior (Capes). O empenho da Abrasco se justificava ante várias razões de elevada relevância, principalmente porque todos os estudiosos brasileiros, dentre eles R. Guimarães (2004) e J. Guimarães (2004), mostram que a pós-graduação stricto sensu no Brasil constitui o nicho da produção, da gestão e da política de ciência e tecnologia do país. É no âmbito das pós-graduações que cresceu aceleradamente o ritmo das pesquisas e o número de grupos de pesquisa do país, num processo de desenvolvimento muito acima da média de incremento da área de ciência e tecnologia em âmbito internacional. Conforme escreve J. Guimarães (2004:307):

Vale destacar que em 1981 o Brasil, com uma produção de 1.887 artigos [indexados no Science Indicators (ISI)] correspondendo a um índice de 0,44\% da produção mundial, ocupava a $27^{\mathrm{a}}$ posição no ranking global da C\&T. Já em 2001, com um total de 10.555 artigos [apenas os computados nessa base de dados], equivalendo a $1,44 \%$ do total mundial, o Brasil subiu nove pontos nessa escala, passando a ocupar a $18^{\mathrm{a}}$ posição. Nesta escalada, foram ultrapassados 13 países, muitos dos quais com longa tradição científica como África do Sul, Áustria, Bélgica, Dinamarca, Escócia, Finlândia, Hungria, Israel, Noruega, Nova Zelândia, Polônia, Tchecoslováquia/República Tcheca e Ucrânia. 
Para que se tenha idéia da dimensão do programa de avaliação da Capes que se constitui como o nicho brasileiro do mais alto nível de formação e celeiro de produção científica, serão mostrados em tabelas e gráficos a seguir alguns dados provenientes das estatísticas da Capes e retirados do site <http://www.capes.gov.br>.

Tabela 1 - Dados gerais da avaliação de 2001-2003

Cursos avaliados: 2.861

Doutorado: 1.020

Mestrado acadêmico: 1.726

Mestrado profissional: 115

Número de programas: 1.819

Número de cursos: 2.861

Alunos titulados: 35.724

Doutorado: 8.094

Mestrado: 25.978

Mestrado profissional: 1.652

Alunos matriculados (dez.): 112.214

Doutorado: 40.213

Mestrado: 66.936

Mestrado profissional: 5.065

Alunos novos (matrícula 2003): 46.648

Doutorado: 11.343

Mestrado: 32.853

Mestrado profissional: 2.452 
Gráfico 1 - Distribuição dos cursos de pós-graduação/região - 2004

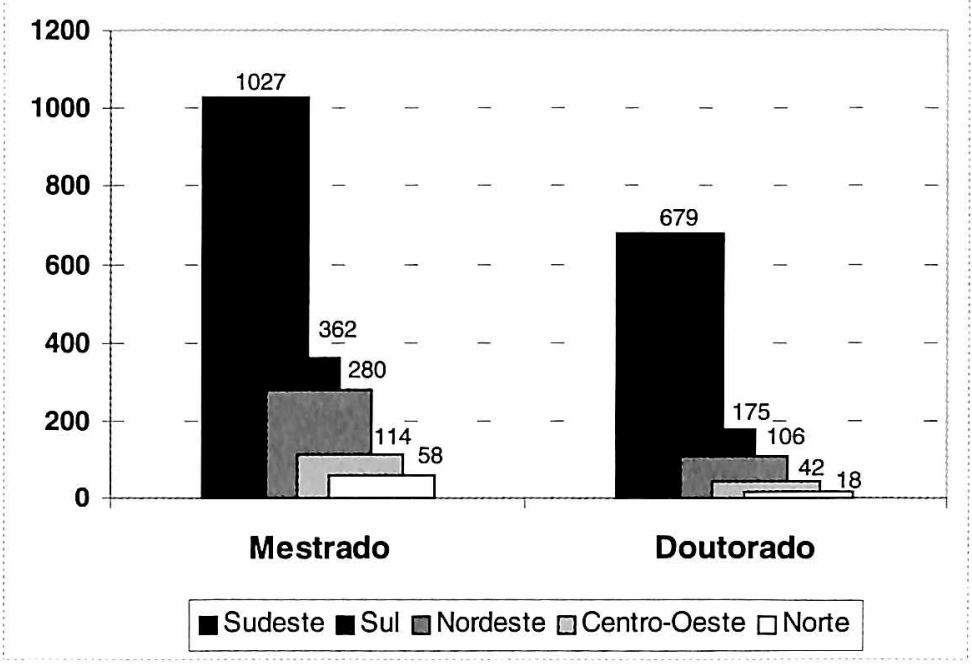

\begin{tabular}{|l|rcr|}
\hline \multirow{2}{*}{ Regiã o } & \multicolumn{3}{|c|}{2004} \\
\cline { 2 - 4 } & Mestrado & Doutorado & Total \\
\hline Norte & 58 & 18 & 76 \\
Nordeste & 280 & 106 & 386 \\
Sudeste & 1.027 & 679 & 1.706 \\
Sul & 362 & 175 & 537 \\
Centro-Oeste & 114 & 42 & 156 \\
\hline Total & 1.841 & 1.020 & 2.861 \\
\hline
\end{tabular}


Gráfico 2 - Distribuição dos programas por grande área do conhecimento 2004

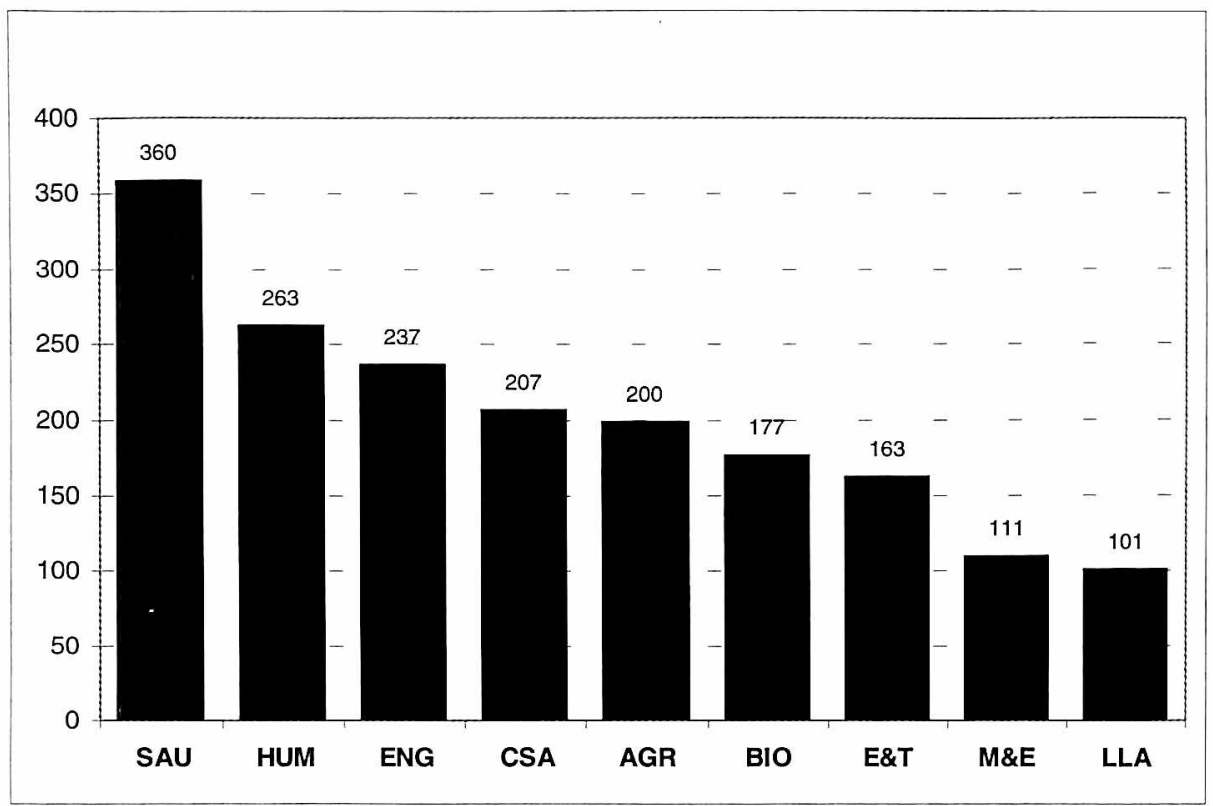

LEGENDA:

SAU - Ciências da Saúde HUM - Ciências Humanas

BIO - Ciências Biológicas ENG - Eng as e C. da Computação M\&E - Multidisciplinar e Ensino CSA - Ciências Sociais Aplicadas LLA - Lingüística, Letras e Artes AGR - Ciências Agrárias

\begin{tabular}{|lrr|}
\hline \multicolumn{1}{|c}{ Grande Área } & 2004 & $\%$ \\
\hline Ciências da Saúde & 360 & 19,8 \\
Ciências Humanas & 263 & 14,5 \\
Eng. ${ }^{\text {as }}$ e C. da Computação & 237 & 13,0 \\
Ciências Sociais Aplicadas & 207 & 11,4 \\
Ciências Agrárias & 200 & 11,0 \\
Ciências Biológicas & 177 & 9,7 \\
Ciências Exatas e da Terra & 163 & 9,0 \\
Multidisciplinar e Ensino & 111 & 6,1 \\
Lingüística, Letras e Artes & 101 & 5,6 \\
\hline Total & 1.819 & $\mathbf{1 0 0 , 0 0}$ \\
\hline
\end{tabular}

Tabela 2 - Evolução da pós-graduação no período 1987-2003

\begin{tabular}{|l|r|r|r|r|r|r|r|r|r|}
\hline & \multicolumn{9}{|c|}{ Anos } \\
\cline { 2 - 9 } & 1987 & 1989 & 1991 & 1993 & 1995 & 1997 & 1999 & 2001 & 2003 \\
\hline Programas & 815 & 919 & 1.019 & 1.120 & 1.230 & 1.274 & 1.424 & 1.551 & 1.819 \\
Titulados - Doutorado & 868 & 1.047 & 1.489 & 1.803 & 2.528 & 3.620 & 4.853 & 6.040 & 8.094 \\
Titulados - Mestrado & 3.647 & 4.727 & 6.811 & 7.609 & 9.265 & 11.922 & 15.380 & 20.032 & 27.630 \\
Alunos novos - Doutorado & 1.786 & 2.416 & 3.509 & 4.132 & 5.331 & 6.199 & 7.903 & 9.101 & 11.343 \\
Alunos novos - Mestrado & 9.440 & 11.432 & 12.768 & 13.633 & 17.746 & 17.570 & 23.837 & 28.074 & 35.305 \\
\hline
\end{tabular}


O investimento da Abrasco no aprimoramento da pós-graduação em Saúde Coletiva tem sido fundamental, apoiando os processos de avaliação da Capes e também promovendo a orientação filosófica, política e dos conteúdos de ciência e tecnologia gerados na área.

Além das razões fundamentais citadas e que dizem respeito ao desenvolvimento do país, houve duas outras motivações muito fortes que empurraram a Abrasco a liderar a iniciativa de realização dessa pesquisa avaliativa exatamente no período de 1995 e 1996 . Vale a pena esclarecêlas, pois ao fazê-lo se identifica com mais nitidez o papel da associação na dinâmica dos programas. A primeira foi gerada externamente e se deveu a uma reação ao processo de organização do Comitê Assessor da Área (CA) pelo CNPq no biênio 1993-1994. Naquele momento conjuntural, havia forte dominância de cientistas das áreas básicas e quantitativas (assim continua, por que não dizê-lo?) nas instâncias decisórias do CNPq. Essas instâncias, desconsiderando lideranças importantes dos programas de pósgraduação e de pesquisa em Saúde Coletiva, haviam organizado um Comitê Assessor da Área - que tem por tarefa avaliar projetos e classificar os pesquisadores na carreira criada pelo $\mathrm{CNPq}$ - com doutores que tinham muito pouca adesão e compreensão do campo da Saúde Coletiva ou eram totalmente externos ao ramo. Eram pesquisadores com elevada e compatível quantidade de artigos publicados em suas disciplinas específicas. Essa decisão contrariou as indicações dos pesquisadores de Saúde Coletiva que tinham direito a voto ${ }^{1}$ e a indicação da Abrasco. Ora, na peculiaridade da organização da área de ciência e tecnologia do país, como já dito, há uma relação quase siamesa entre os resultados de avaliação da Capes - a qual avalia o mérito e classifica os programas de pós-graduação - e o julgamento de mérito dos pesquisadores e de suas pesquisas pelo CNPq.

Certamente, depois de todos os protestos e intervenções cabíveis no CNPq, reagindo à forma como foi constituído o Comitê Assessor (CA), a diretoria da Abrasco resolveu partir para uma atuação diferenciada que marcasse sua posição e lhe permitisse afirmar e reafirmar a identidade e a qualidade da produção em Saúde Coletiva. Decidiu-se então fazer uma avaliação dos programas de pós-graduação (PPG), com base nas relevâncias estabelecidas pela própria associação, mas dentro dos parâmetros científicos do campo da avaliação de ciência e tecnologia. Agindo dessa maneira, a

\footnotetext{
${ }^{1} \mathrm{O}$ CNPq, cada vez que vai escolher a composição de um novo Comitê Assessor (CA) da área, faz ampla consulta aos pesquisadores de carreira que a compõem e que estão classificados no nível 1 $(\mathrm{A}, \mathrm{B}, \mathrm{C})$ e também às instituições científicas que representam a área. $\mathrm{O}$ nível 1 congrega os investigadores mais experientes e produtivos no sistema de ciência e tecnologia do país.
} 
associação tentava vocalizar suas reivindicações, apoiada em dados e informações valiosos, desmontando uma razão apenas instrumental e reducionista do campo de conhecimento em Saúde Coletiva. Em momento algum a instituição questionou as normas e os critérios do CNPq e da Capes, o que não teria sentido algum.

No caso da sua pesquisa avaliativa, a Abrasco buscou e conseguiu apoio técnico e financeiro das duas instituições (CNPq e Capes) e fez um trabalho integrado com elas, o que deu também mais legitimidade às informações que trouxe com a pesquisa avaliativa. Fazendo uma analogia com a teoria dos sistemas que aumentam seu nível de complexidade e resposta quando há ruídos ou crises (Atlan, 1991), a diretoria da associação conseguiu transformar a dificuldade de compreensão que ocorreu nas relações com o CNPq em matéria para seu crescimento e desenvolvimento.

A segunda razão para a abrangente avaliação de 1995-1996 foi endógena. Dois problemas recorrentemente se apresentavam quase como estruturantes do imaginário dos profissionais do campo. Um deles, o mais sério e quase sem solução, ${ }^{2}$ é o que diz respeito à delimitação da área, cujo encaminhamento, naquele momento (1995-1996), se afigurava como crucial. Havia, no âmbito da Capes, ou sem o conhecimento dessa agência, vários pleitos e iniciativas de criação de programas novos, muitos deles de forma totalmente oportunista. No cumprimento da Lei de Diretrizes e Bases, o Ministério da Educação estava pressionando as instituições de ensino superior (sobretudo as privadas) para que aumentassem o seu nível de qualidade. Um dos fortes requisitos dessa classificação (em faculdades, centros universitários ou universidades, em ordem crescente) era que nas instituições de ensino superior houvesse um certo número de programas de pós-graduação stricto sensu. Muitas dessas entidades, premidas pelo interesse de preservar seu status e seu nome, consideraram que um dos mais fáceis programas a serem criados seria o de 'Saúde Coletiva', uma vez que este não exigia grandes investimentos em equipamentos e laboratórios. Tais decisões estavam sendo tomadas à revelia da Abrasco (e, freqüentemente, da Capes) sem que as instituições tivessem tradição na área ou professores com formação específica. Algumas delas chegaram a reunir doutores das mais distintas e impróprias formações para a Saúde Pública, acreditando que conseguiriam aprovar seus programas na Capes.

\footnotetext{
${ }^{2}$ Numa reunião sobre periódicos científicos realizada nos Estados Unidos em 2005, todos os editores se queixavam das dificuldades encontradas para delimitar o campo da 'Saúde Pública'.É importante lembrar também que o termo 'Saúde Coletiva' é uma invenção brasileira - sendo aos poucos adotado em alguns países da América Latina - e o termo 'Saúde Pública' é universal.
} 
O outro motivo interno foi que, deveras, havia muitos mitos sobre a pós-graduação em Saúde Coletiva que vinham sendo reproduzidos pelos próprios profissionais da área. Alguns diziam que 'Saúde Coletiva' seria uma área cientificamente nova e imatura e que a Capes deveria ter condescendência ao julgar os programas, não devendo compará-los com os de outros setores. Outros julgavam que havia um tal grau de peculiaridade nesse campo que o julgamento do mérito de seus cursos e professores não poderia seguir padrões e normas estabelecidos para todos. Outros ainda, e no mesmo sentido do segundo argumento, diziam que as publicações científicas dos pesquisadores em Saúde Coletiva tinham elevada relevância acadêmica e social, mas eram incompatíveis com os critérios estabelecidos pela Capes. A razão principal deste último 'mito' era uma contraposição de muitos pesquisadores da área à avaliação da Capes, que priorizava a publicação de artigos na crença de que a maioria das obras dos doutores e pesquisadores dos programas de Saúde Coletiva, menos os de epidemiologia, se constituísse de livros, relatórios e informes técnicos.

Transformou-se a pesquisa avaliativa, portanto, numa necessidade. E seus resultados puderam esclarecer muitas questões obscuras para dentro e para fora da associação. Para dentro, vários mitos foram desvelados e serão tratados a seguir. Esse estudo partiu de algumas hipóteses:

1. A pós-graduação em Saúde Coletiva usufrui dos méritos e dos problemas de todos os programas semelhantes no país. Essa hipótese assinala o óbvio reconhecimento de que a área não está nem deve ficar fora do contexto nacional e internacional de ciência e tecnologia. Mas leva em conta, também, algumas características específicas: inexiste graduação em Saúde Pública/Coletiva, o que dificulta a assimilação de conceitos; ela trabalha com pessoas das mais diferentes formações; e constitui uma área de conhecimento que tem uma articulação intrínseca com políticas públicas e práticas, desde os precursores do século XIX (Nunes, 1999).

2. Existe uma progressiva mudança no perfil de demanda pelos cursos, sobretudo de mestrado. De uma clientela oriunda de universidades e centros de pesquisa, a procura dos programas estaria se encaminhando prioritariamente para abranger gestores e profissionais do serviço. Essa inflexão significaria uma busca por qualificação desses atores (que atuam na prática) e estaria impulsionada pela revolução da sociedade do conhecimento e do mercado público e privado de trabalho em saúde, cada vez mais rigoroso quanto à formação dos profissionais. 
3. Há uma exigência social de que os estudantes de pós-graduação sejam mais bem formados quanto a conteúdos e técnicas. Nessa hipótese, se assume a crítica cada vez mais persistente de ex-alunos e das instituições quanto ao 'saber fazer'. O conteúdo teórico e pragmático da formação estaria sendo subsumido por uma orientação discursiva geral e política do setor. Portanto, haveria uma demanda à Abrasco para que ela arbitrasse uma agenda mínima de conteúdos, produtos e metodologias de abordagem da realidade.

A pesquisa avaliativa teve forte componente de auto-avaliação no sentido estrito do termo, considerando-se a auto-avaliação como o primeiro passo para o caminho da aprendizagem e de transformação na condução do processo avaliativo, na medida em que conta com a contribuição de todos os atores envolvidos nos processos em análise. No caso, coordenadores dos programas iniciaram uma dinâmica interna de consulta e redigiram documentos, configurados conforme padrões de desempenho da própria instituição e sem o propósito de classificação ou de comparação com outras áreas.

O processo de investigação liderado pela Abrasco teve, principalmente, o propósito de abranger outras questões que a avaliação da Capes, por causa dos seus objetivos, não conseguia aprofundar. Interessava à Abrasco saber, pela sua missão de promover o pensamento e a prática de Saúde Pública, qual seria o arcabouço da formação científica da área e se ela se coadunava com os princípios e a filosofia que a associação professa; quem é quem na demanda pelos cursos de mestrado e doutorado da área, uma vez que, em sua totalidade, os programas estão abertos a múltiplas formações e profissões; e também onde estão e o que fazem os egressos dos programas. Não foi possível estender para uma avaliação dos egressos - embora esta fosse uma meta proposta no projeto de pesquisa - sobre a qualidade e a adequação dos cursos a suas necessidades, ficando essa indagação para um momento posterior.

A investigação contou com a colaboração de consultores externos, nacionais e internacionais, e ocorreu num momento privilegiado de inflexão em que todas as vozes que atuam no setor educacional e de ciência e tecnologia no país se ergueram para reconhecer os êxitos dos trinta anos do sistema de pós-graduação brasileiro (Bevilacqua, Gutierrez \& Bevilacqua, 1996; Gazolla, 1996; Guimarães, 1996; Krieger, 1996). Os resultados do estudo da Abrasco revelaram que realmente a área de Saúde Coletiva tinha todos os méritos do sistema e padecia dos mesmos problemas que ele, exigindo sua adequação às céleres mudanças da sociedade pós-industrial. No entanto, foram encontradas peculiaridades. Os problemas são resumidos 
num decálogo, conforme Minayo (1997) e outros avaliadores (Goldenberg \& Schenkman, 1997; Nunes \& Costa, 1997; Tanaka, 1997):

1. Níveis diferenciados de qualidade dos cursos e grupos de pesquisa, denotando enormes desequilíbrios regionais. Por exemplo: não havia e continua a não existir programa de pós-graduação stricto sensu em Saúde Coletiva na Região Norte. Recentemente, firmou-se parceria entre o Centro de Pesquisas Leônidas e Maria Deane (Fiocruz), a Universidade Federal do Amazonas e a Universidade Federal do Pará, que resultou na criação de um mestrado interinstitucional. Entretanto, essa iniciativa, na qual se contemplam linhas de investigação em saúde, está vinculada ao comitê interdisciplinar da Capes.

2. Falta de clareza nos diferentes níveis de formação (entre mestrado e doutorado), causando vários problemas relativos à duração dos cursos, ao ensino enciclopédico, ao forte apego institucional ao modelo seqüencial de pós-graduação, à exigência de mestrado como pré-requisito para doutorado, dentre outros.

3. Elevado índice de evasão de estudantes, em algumas áreas e em alguns cursos (sobretudo os que mais recebem estudantes que trabalham nos serviços públicos), exigindo repensar a rigidez da organização dos programas para estes se adequarem à pessoa, e não o contrário.

4. Perda de pessoal altamente qualificado que não pode ser contratado, por falta de mecanismos institucionais de absorção nos quadros de pesquisadores e docentes.

5. Aporte insuficiente e instável de recursos (humanos e materiais), impedindo a consolidação de programas e investimentos em infraestrutura.

6. Rigidez nos modelos e regulamentos dos cursos, levando suas coordenações a valorizarem normas fechadas e limitadoras em lugar de priorizarem acima de tudo o processo de ensino/aprendizagem, o ritmo dos estudantes e a expressão cabal da potencialidade deles.

7. Desperdício da capacidade de pesquisa e de orientação, em muitos programas, deixando possíveis doutores ociosos, pelas dificuldades ou mesmo pela incapacidade dos gestores institucionais de prover adequação logística e administrativa. 
8. Avaliação dos programas por 'médias' e não por desempenho individual, encobrindo, por vezes, participação medíocre de professores dos cursos e subvalorizando a contribuição dos mais produtivos.

9. Ausência de estratégias que relacionem os programas com o setor de serviços de saúde, repercutindo em falhas práticas na formação dos estudantes.

10.Escasso entrosamento dos programas da área com a graduação, contrariando um dos objetivos fundamentais do sistema de pósgraduação, que é preparar quadros altamente qualificados para o ensino superior.

Alguns pontos específicos da área serão agora assinalados:

1. No que concerne à qualidade dos cursos, o caráter multiprofissional e multidisciplinar da área, como prática e teoria, requer uma 'articulação equilibrada dos saberes' que combina aspectos biológicos, psicológicos, sociais e ambientais. $O$ estágio científico e tecnológico atual evidencia uma 'insignificante presença das ciências biológicas e ambientais e da demografia' e quase nula da 'economia', sob o ponto de vista e sob a lógica da Saúde Coletiva (e não do mercado do setor saúde).

2. O debate do conteúdo da formação, numa área eminentemente multidisciplinar, suscita o tema crucial do 'núcleo comum de conhecimentos e práticas específicos', como parâmetro de identidade que, uma vez atendido, se transforma em instrumento de autonomia para que cada pós-graduação possa acrescentar outros conteúdos e atividades de acordo com seus interesses peculiares.

3. O debate sobre matérias concretas evoluiu para uma formulação mais abstrata e condizente com uma pedagogia contemporânea de enfatizar formação, reflexão, habilidades e criatividade que se esperam de um mestrando e de um doutorando, conforme registra Minayo (1997:63):

O mestrando e o doutorando em Saúde Coletiva precisam ser preparados para gerar, aperfeiçoar, dominar e empregar conhecimentos científicos e tecnologias, com o objetivo de produzir bens e serviços de qualidade e apropriados às necessidades de saúde no país. Desta forma é preciso investir numa completa revisão metodológica e de conteúdo, adequando os cursos às exigências históricas. Não se trata de ensinar um pouco de quase tudo $\mathrm{e}$ nem tudo de quase nada, mas de combinar a formação interdisciplinar com as necessidades e potencialidades de cada um dos estudantes. Por isso, é preciso desregular os excessos e tornar a Pós-Graduação mais flexível. 
Tentando vocalizar as reflexões resultantes da pesquisa avaliativa, Minayo (1997:65) continua:

A mudança metodológica mais importante para enfrentar o avanço científico e tecnológico e evitar a obsolescência é investir no aprender a aprender, enfatizar a experimentação das metodologias de pesquisa, proporcionar ambiência acadêmica necessariamente crítica e plural (seminários, congressos, hábitos de leitura de periódicos científicos de ponta, escrita de artigos, discussões sobre ética e política, filosofia, tradição e inovação), além da familiarização com sistemas de comunicação, informação e informática.

A coordenadora da pesquisa avaliativa continua sua argumentação dizendo que é fundamental evitar-se a compartimentalização do saber, buscando novas formas de ensinar, investindo em informação, informática e capacidade de análise e de domínio de línguas estrangeiras. Acrescenta que é importante, inclusive, ajudar os estudantes a desenvolverem sua capacidade gerencial, uma vez que aqui e em vários países do mundo independentemente da área de formação de seus phDs - sobretudo os doutores estão em cargo de responsabilidade tanto nos governos quanto nas universidades e nas empresas privadas de ponta (Minayo, 1997).

4. A pesquisa avaliativa ressaltou também a excessiva rigidez dos programas organizados de forma tradicional, ou seja, muito mais na lógica de 'passar conteúdos', muitas vezes repetindo-os nos níveis de mestrado e doutorado. A falta de clareza e de adequação dos cursos ao perfil da demanda foi constatada principalmente nos cursos de mestrado, cuja clientela era, na maioria, formada por profissionais inseridos nos serviços do Sistema Único de Saúde (SUS) ou seus gestores. Essa constatação posteriormente gerou um importante debate sobre o mestrado profissional uma saida, segundo alguns, 'controversa', que o sistema Capes encontrou para incluir a demanda referente à formação de alto nível para profissionais muito mais interessados em reflexões e instrumentos conceituais e técnicos voltados para a prática - e também necessitados desses instrumentos e reflexões - do que em seguir carreira de pesquisadores. Na ocasião houve uma discussão inconclusa entre os avaliadores, sobre se deveria ou não haver mestrado acadêmico (ou apenas o profissionalizante) na pós-graduação em Saúde Pública. Essa decisão implicaria que os candidatos a pesquisadores doutores fizessem apenas o curso de doutorado, pois o mestrado seria parte inclusiva da organização do doutorado, como ocorre em vários países da Europa. A rigidez dos cursos, tratada há pouco, foi indicada como responsável pelo excessivo tempo que um estudante passava fazendo pós-graduação 
em Saúde Pública - em alguns programas, até a metade dos anos 90, os estudos se delongavam até 11 anos -, com prejuízos para o país, para os estudantes e para as instituições (Minayo, 1997; Tanaka, 1997).

5. No que concerne às publicações científicas, os estudos qualitativos (Luz, 1997) e cientométricos realizados na época revelaram uma agradável surpresa, que se coaduna com o que foi aqui apresentado por J. Guimarães (2004): forte tendência ao crescimento, cerca de $20,6 \%$ ao ano, sendo que de 1990 a 1995 o aumento foi de $155 \%$ (Viacava \& Leitão, 1997). Esse período coincide com a abertura de alguns cursos altamente produtivos, com mudanças qualitativas realizadas no programa e o incentivo da Abrasco à melhoria da qualidade e do desempenho dos programas. Como seria de se esperar, numa área que junta pesquisadores, profissionais que atuam no serviço e gestores, a modalidade mais comum de produção científica assinalada eram as apresentações em congressos. No entanto, dizem os avaliadores, 'é notável o incremento do número de artigos, livros e capítulos de livros'. A pesquisa avaliativa dirimiu o 'mito' segundo o qual os profissionais da área publicavam pouco ou não publicavam artigos, inclusive na área de ciências sociais e saúde.

Mas a avaliação evidenciou também pontos problemáticos. $\mathrm{O}$ estudo mostrou muita dispersão da produção científica por periódicos e o relativamente baixo grau de internacionalização das publicações (Viacava \& Leitão, 1997). Certamente, a criação da revista Ciência \& Saúde Coletiva, no final de 1996, e da Revista Brasileira de Epidemiologia, em 1998, passou a contribuir para direcionar melhor a demanda por publicação, juntandose aos veículos mais tradicionais existentes, como Revista de Saúde Pública (USP) e Cadernos de Saúde Pública.

6. Do ponto de vista da situação dos egressos, a grata surpresa foi constatar que na sua quase totalidade os mestres e doutores estavam empregados nas instituições de ensino superior ou nos serviços de saúde. A maioria estava trabalhando no setor público, alguns tinham duplo vínculo público/ privado e uma minoria estava em atividade em instituições nãogovernamentais (Goldenberg \& Schenkman, 1997).

Os resultados da pesquisa avaliativa foram objeto de um seminário amplo em que participaram todos os coordenadores dos programas, vários pesquisadores seniores da área, representantes da Organização Pan-Americana da Saúde (Opas/Washington) no Brasil, representantes das diretorias de avaliação do CNPq e da Capes e dois consultores internacionais, um dos Estados Unidos e outro da França. Esse 
seminário focalizou os problemas assinalados pela investigação - cujos dados constam no número temático de Ciência \& Saúde Coletiva, 2(1/2), 1997 -, buscando encaminhar as questões mapeadas como sendo as mais cruciais: 'ter ou não ter um núcleo comum de disciplinas'; 'qualidade dos cursos'; 'política de produção e de divulgação científica'. Seu resultado está publicado em artigo de Minayo \& Costa (1998).

Sobre a questão 'núcleo comum de conhecimentos e práticas', os participantes do seminário elaboraram algumas diretrizes para os conteúdos curriculares:

1. 'Bases conceituais e históricas' que incluam: a) história e cultura da Saúde Coletiva/Saúde Pública; b) saúde como tema relevante para a sociedade e objeto de interesse das ciências sociais; c) saúde como objeto de políticas públicas e sociais; d) processos e perfis de adoecimento como objeto da epidemiologia; e) saúde como prática de promoção, de prevenção, recuperação e organização de serviços assistenciais.

2. 'Bases técnico-instrumentais': habilidades para uso de metodologias e técnicas quantitativas e qualitativas e de conhecimentos básicos para aplicá-las.

3. 'Formação geral': a) foco nas dimensões filosóficas e humanísticas; b) formação para liderança em C\&T; habilidades de informática e orientação para teorias e uso das informações e da comunicação; proficiência em alguma língua estrangeira; aprendizado de atualização permanente, significando 'ambiente de aprender a aprender'.

Os itens citados não se constituem como um receituário e sim como um guia de orientação, tanto para os programas que venham a se constituir como para o julgamento dos existentes.

Sobre a 'qualidade dos cursos', as principais recomendações podem ser resumidas em três parâmetros: a) ênfase na estruturação intrínseca dos programas, atendendo aos critérios apresentados há pouco e aos requisitos estabelecidos pela Capes em seu sistema de avaliação; b) ênfase na qualidade institucional da universidade ou dos institutos de pesquisa, incluindo-se aí a qualificação dos corpos docentes; c) ênfase no critério de relevância social para a existência do programa, no lugar onde ele se institui.

Daí surgiram algumas recomendações endereçadas às instituições, principalmente às que estavam 'se aventurando' em abrir cursos indistintamente: a) proporcionar infra-estrutura específica para o programa; b) ter um núcleo de epidemiologistas e cientistas sociais em saúde 
(antropologia, políticas, administração e planejamento); c) assentar os programas de pós-graduação em núcleos de pesquisa; d) valorizar tanto os componentes de formação geral como os técnicos e metodológicos (o saber fazer) e os de formação humanística e filosófica; e) promover parcerias entre os programas e entre grupos de pesquisa.

Sobre 'a produção e a divulgação científica', os participantes do seminário recomendaram forte investimento dos editores nas revistas da área, em sua qualidade, divulgação, periodicidade e indexação. Um item especial de discussão foi a publicação de livros, bastante habitual na ampla área de Saúde Coletiva e que padece de subestimação sobretudo na avaliação periódica da Capes. Esse ponto, talvez o mais dificil de ser enfrentado nos processos de análise de desempenho individual e institucional, continua ainda como questão não resolvida adequadamente. A pontuação atualmente estabelecida pelos comitês de avaliação (um livro publicado em editora que tem comissão científica equivalendo ao peso de meio artigo) constitui um imperdoável equívoco que só pode ser sanado por uma avaliação qualitativa das publicações. Esse critério é também, sem sombra de dúvida, concessão aos critérios de indexação de outras disciplinas que praticamente só trabalham com artigos e revela a dificuldade da área de Saúde Coletiva de avaliar a qualidade desse tipo de produção intelectual.

Nas conclusões dos resultados da avaliação, Minayo \& Costa (1998) chamaram a atenção para alguns desafios que continuam atuais: a) criar critérios de avaliação que permitam valorizar tanto a relevância acadêmica como a importância social da produção científica; b) definir com mais clareza o que é produção tecnológica em Saúde Coletiva; e c) manter sempre a saudável tensão entre estudos básicos, estratégicos e operacionais - todos de grande importância tendo em vista as necessidades de saúde da população brasileira.

Um dos mais importantes resultados do seminário foi a decisão da diretoria da Abrasco de instituir, em caráter permanente, um fórum dos coordenadores de programas de pós-graduação da área de Saúde Coletiva/ Saúde Pública/Medicina Preventiva. Esse coletivo começou a funcionar desde então, constituindo-se num espaço de socialização, vocalização, tomada de decisões coletivas e de diálogo com os representantes da área na Capes e no CNPq.

O coletivo dos coordenadores de pós-graduação tem cumprido a missão para a qual foi criado, permitindo a todos expressarem suas idéias e reivindicações aos representantes na Capes e no CNPq e, sobretudo, se constituindo num lócus de vocalização dos cursos mais novos e menos experientes. É inevitável que ele tenha um viés corporativo, muitas vezes 
canalizando queixas e reclamações contra os órgãos de fomento e avaliação por meio dos representantes de área. Por causa do justo aspecto de canal de defesa de interesses, o fórum de pós-graduação não substitui o processo avaliativo que a Abrasco deveria assumir periodicamente, tratando de aspectos fundamentais de orientação da formação no setor, que nem o CNPq nem a Capes tem como missão desenvolver e liderar.

Em 1996, quando a pesquisa avaliativa da Abrasco terminou, o tradicional relatório da Capes assinalava a existência de 16 programas: nove de mestrado e sete com mestrado e doutorado, $166 \%$ a mais do que os que existiam em 1981, quando se tem memória da primeira avaliação. O número dos programas de 1996 correspondia a 7,0\% do total de 228 da grande área da saúde. A página da Capes (<http://www.capes.gov.br >) referente à avaliação de 2003 (último ano de avaliação completa) registra 38 programas reconhecidos na área de Saúde Coletiva - significando, nesses dez anos, um crescimento de $137 \%$, crescimento esse fortemente monitorado pelos representantes da área e da grande área, pelos motivos já aludidos. Em 2006, segundo dados da Capes, a grande área de 'ciências da saúde' apresenta um conjunto de 421 cursos reconhecidos, estando nos primeiros lugares, em número, medicina e odontologia. Em terceiro vem a Saúde Coletiva, com 9,2\% do total. Dos programas existentes na área de Saúde Coletiva, três estão classificados no nível 06 (grau de excelência elevado), dez no nível 05 (excelentes), oito no nível 04 (muito bons), 17 no nível 03 (regulares). Há ainda nove dos melhores programas que têm mestrado profissional atendendo às demandas dos que atuam nos serviços e na gestão. Esse balanço comparativo revela o quanto houve de aumento quantitativo e qualitativo, comparativamente, entre 1981 e 1996 e de 1996 a 2006. A Tabela 3 mostra a localização da Saúde Coletiva na grande área das 'ciências da saúde'. 
Tabela 3 - Mestrados/doutorados reconhecidos na grande área da saúde 2006

\begin{tabular}{|c|c|c|c|c|c|c|c|c|c|}
\hline \multirow{3}{*}{ Área (Área de avaliação) } & \multicolumn{5}{|c|}{ Grande Área: Ciências da Saúde } & & & & \\
\hline & \multicolumn{5}{|c|}{$\begin{array}{l}\text { Programas e cursos } \\
\text { de pós-graduação }\end{array}$} & \multicolumn{4}{|c|}{$\begin{array}{l}\text { Totais de cursos } \\
\text { de pós-graduação }\end{array}$} \\
\hline & Total & M & $\mathrm{D}$ & $\mathrm{F}$ & $\mathrm{M} / \mathrm{D}$ & Total & M & $\mathrm{D}$ & $\mathrm{F}$ \\
\hline EDUCAÇÃO FÍSICA & 17 & 9 & 0 & 0 & 8 & 25 & 17 & 8 & 0 \\
\hline ENFERMAGEM & 28 & 12 & 1 & 3 & 12 & 40 & 24 & 13 & 3 \\
\hline FARMÁCIA & 27 & 10 & 0 & 2 & 15 & 42 & 25 & 15 & 2 \\
\hline $\begin{array}{l}\text { FISIOTERAPIA E } \\
\text { TERAPIA OCUPACIONAL }\end{array}$ & 5 & 4 & 0 & 0 & 1 & 6 & 5 & 1 & 0 \\
\hline $\begin{array}{l}\text { FONOAUDIOLOGIA } \\
\text { (EDUCAÇÃO FÍSICA) }\end{array}$ & 8 & 4 & 0 & 1 & 3 & 11 & 7 & 3 & 1 \\
\hline MEDICINA (MEDICINA I, II, III) & 191 & 34 & 12 & 6 & 139 & 330 & 173 & 151 & 6 \\
\hline NUTRIÇÃO (MEDICINA II ) & 13 & 7 & 0 & 1 & 5 & 18 & 12 & 5 & 1 \\
\hline ODONTOLOGIA & 94 & 28 & 6 & 14 & 46 & 140 & 74 & 52 & 14 \\
\hline SAÚDE COLETIVA & 38 & 16 & 0 & 9 & 13 & 51 & 29 & 13 & 9 \\
\hline Total de CIÊNCIAS DA SAÚDE & 421 & 124 & 19 & 36 & 242 & 663 & 366 & 261 & 36 \\
\hline
\end{tabular}

Fonte: Capes - <http://www.capes.gov.br>. Data da última atualização: 6/3/2006.

Cursos: M - Mestrado acadêmico; D - Doutorado; F - Mestrado profissional.

Qualitativamente, também é possível saber o que avançou na pósgraduação em Saúde Coletiva nos últimos dez anos, posteriores à pesquisa avaliativa. O relatório de área do período de 1998 a 2000 e um texto de Goldbaum (2001) assinalam: a) os cursos aprovados guardavam elevado grau de coerência com os campos disciplinares e áreas de concentração apropriadas; b) possuíam corpo docente com elevada qualificação e adequação; c) também foram constituídos ou reorganizados grupos de pesquisa mais bem estruturados, se comparados com o período anterior de avaliação; d) havia diminuído o tempo médio para titulação de mestres e doutores; e) a produção intelectual havia crescido e os representantes da área na Capes haviam buscado critérios de avaliação que contemplassem, nessa produção, legitimidade científica e social. 
O documento chama a atenção para três pontos que continuam problemáticos: a) baixa capacidade de absorção de doutores, altamente qualificados, pela falta de abertura de concursos para contratação nas instituições de ensino superior; b) dificuldades de acesso dos professores e orientandos a periódicos internacionais; e c) a pouca valorização dada pelo comitê de avaliação da grande área da saúde aos periódicos editados no país, impedindo a identificação de políticas editoriais que atendam às necessidades nacionais e regionais (Relatório de Área, apud Goldbaum, 2001).

O Documento de Avaliação de Área referente a 2001-2003, relativo à última avaliação completa realizada pelo sistema Capes, inicia suas considerações dizendo que: a) a Saúde Coletiva no Brasil constitui-se hoje como um campo plenamente consolidado, apresentando melhora em todos os indicadores; b) os programas estão presentes em todas as regiões do país, com exceção da Região Norte; c) todos se norteiam pelos critérios e processos estabelecidos pela Capes para o aperfeiçoamento da pósgraduação; d) há presença e influência dos programas internacionais, sobretudo no âmbito da América Latina; e) professores e/ou pesquisadores passaram a participar dos comitês técnico-científicos brasileiros e de organismos internacionais; f) houve um crescimento no número dos grupos de pesquisa (por exemplo, o Diretório do CNPq registra quatrocentos e cerca de 2.500 pesquisadores na área de Saúde Coletiva no ano de 2003); g) a produção científica vem se consolidando e apresentando tendências de internacionalização. O relatório reafirmou pontos assinalados na avaliação de 1998-2001: coerência dos campos disciplinares; elevada qualificação do corpo docente; melhor organização dos grupos de pesquisa; diminuição do tempo médio de titulação dos estudantes.

Esse relatório também assinala problemas: a) alguns programas têm dificuldade de definição de linhas de pesquisa, evidenciando a pouca experiência no campo da investigação; b) alguns programas ainda utilizam docentes não especificamente qualificados (por exemplo, médicos, epidemiologistas e outros) para ministrar disciplinas na área de ciências sociais e humanas; c) ainda é muito tímida a presença da produção discente no conjunto da divulgação científica da área. Uma questão de interesse para a Abrasco é que, embora a revista Ciência \& Saúde Coletiva, por ocasião dessa avaliação, já estivesse indexada em várias bases de dados internacionais, classificada como 'A nacional' e tendo importante repercussão internacional, o relatório apenas assinala como importantes periódicos da área a Revista de Saúde Pública e os Cadernos de Saúde Pública. O documento evidencia as contradições internas e as pressões de outros setores da Capes, pois ao passo que os avaliadores reclamam da 
pouca valorização das publicações nacionais, desconhecem a revista da associação que os representa, periódico que está em pleno crescimento e desenvolvimento, como se pode constatar em outro texto deste livro.

\section{Conclusões}

Buscou-se aqui apresentar o processo pelo qual a Abrasco - que tem o termo 'pós-graduação' na constituição de seu nome, 'Associação Brasileira de Pós-Graduação em Saúde Coletiva' - atuou e vem atuando na consolidação dessa área acadêmica, mantendo a especificidade que marca a origem desse campo de conhecimentos e práticas. Essa especificidade pode ser traduzida no fato de que os conhecimentos científicos caminham pari passu com o desenvolvimento dos serviços de atenção à saúde e são estratégicos para a gestão do SUS. Muitas mudanças vêm sendo observadas no âmbito da pós-graduação lato sensu, tema que mereceria uma pesquisa avaliativa, além de ações políticas reclamadas em todos os documentos específicos, como cita Belisário (2002).

Na pós-graduação stricto sensu, a mesma peculiaridade não impede que a Abrasco e todos os programas de pós-graduação se ajustem aos critérios universais de avaliação da ciência, representados pelo sistema Capes. A Capes segue padrões internacionais, fazendo a avaliação por pares acadêmicos e incluindo a auto-avaliação institucional como parte da metodologia. Também e cada vez mais essa instituição inclui investigadores de outros países nos comitês de avaliação, o que garante aos programas comparabilidade quanto aos critérios de excelência.

Historicamente se pode observar que a Abrasco acompanhou a pósgraduação com estudos e avaliações, propiciando informações estratégicas às instituições. A pesquisa avaliativa realizada nos anos de 1995-1996 constituiu a mais importante inflexão da associação sobre o tema, produzindo conhecimentos que foram estratégicos para a reorganização de muitos programas, e passou a dar parâmetros a respeito de vários aspectos problemáticos, tanto aos coordenadores de curso como às instituições de avaliação e de fomento. O sentido de enfatizar esse processo, no presente texto, se deve à importância conjuntural da iniciativa que acabou por se constituir num ponto crucial para ampliar a complexidade das reflexões num fórum específico e para dar subsídios aos representantes de área.

Em resumo, não há uma colisão entre os interesses da Abrasco e da Capes na avaliação em Saúde Coletiva. Ambas as instituições trabalham para o interesse do país e da qualidade científica e tecnológica do que é gerado no setor. No entanto, essas duas entidades têm finalidades e 
compromissos diferenciados. Da Capes se exige rigor nos critérios e no uso de indicadores, o que lhe permite oferecer ao país uma série histórica de desenvolvimento do nível mais alto da formação educacional do Brasil e comparabilidade entre grandes áreas e entre áreas dentro de grandes áreas, assim como dos programas entre si e de cada programa a partir de sua própria história e evolução. Essa ingente missão possibilita-lhe, também, comparabilidade em âmbito internacional.

Da Abrasco, a sociedade brasileira, o setor saúde e, em especial, a área de Saúde Coletiva esperam orientação filosófica e política para o encaminhamento dos rumos teóricos, metodológicos e práticos da formação stricto e lato sensu. É por isso que, celebrando os dez anos da pesquisa avaliativa que se configurou como um marco fundamental para a identidade e a construção da área, seria muito importante que outra inflexão fosse feita, certamente guiada por novas perguntas e novos desafios. E também, como já foi dito, que os outros níveis de formação como a graduação, a especialização e a residência pudessem merecer investimento reflexivo aprofundado.

Não há dúvidas de que a Abrasco, em seu papel específico na formação de recursos humanos de alto nível para o SUS, é uma instituição de sucesso. No entanto, há muito caminho a percorrer e a abrir, fazendo com que sua identidade originária possa ser permanentemente rejuvenescida e 'complexificada'.

\section{REFERÊNCIAS BIBLIOGRÁFICAS}

ABRASCO. Em nome da Saúde Pública/Saúde Coletiva. Boletim Abrasco, dez.2005.

ATLAN, H. L'intuition du complèxe et ses theorizations. In: SOULIÉ, F. F. (Org.) Les Théories de la Complexité Autour de l'Ouevre d'Henri Atlan. Paris: Éditions de Seuil, 1991.

BELISÁRIO, S. A. Associativismo em Saúde Coletiva : um estudo da Associação Brasileira de Pós-Graduação em Saúde Coletiva (Abrasco), 2002. Tese de Doutorado em Saúde Coletiva, Campinas: Faculdade de Ciências Médicas da Universidade Estadual de Campinas (Unicamp). (Mimeo.)

BEVILACQUA, L.; GUTIERREZ, R. H. \& BEVILACQUA, H. Formação de pessoal pós-graduado e pesquisa no Brasil. In: CAPES. Discussão sobre a PósGraduação Brasileira. Brasília: Editora UnB, 1996. p.25-35.

CONH, A. \& NUNES, E. D. Relatório do Encontro Nacional de Pós-Graduação em Saúde Coletiva e Reforma Sanitária. Estudos de Saúde Coletiva. Rio de Janeiro: Abrasco, 1988.

FUNDAÇÃO COORDENAÇÃO DE APERFEIÇOAMENTO DE PESSOAL DE NÍVEL SUPERIOR. Avaliação da Pós-Graduação. Disponível em: <http:// www.capes.gov.br>. Acesso em: 22.mar.2006. 
FUNDAÇÃO COORDENAÇÃO DE APERFEIÇOAMENTO DE PESSOAL DE NÍVEL SUPERIOR. Avaliação da Pós-Graduação. Documento de área: Saúde Coletiva (1998-2000). Disponível em: <http://www.capes.gov.br>. Acesso em: 22.mar.2006.

FUNDAÇÃO COORDENAÇÃO DE APERFEIÇOAMENTO DE PESSOAL DE NÍVEL SUPERIOR. Avaliação da Pós-Graduação. Documento de área: Saúde Coletiva (2001-2003). Disponível em: <http://www.capes.gov.br>. Acesso em: 22.mar.2006.

GAZOLLA, A. L. A. Evolução das formas de organização da pós-graduação brasileira. In: CAPES. Discussão sobre a Pós-Graduação Brasileira. Brasília: Editora UnB, 1996. p.88-97.

GOLDBAUM, M. Avaliação da pós-graduação em Saúde Coletiva no Brasil Editorial. Cadernos de Saúde Pública, 17(6):1-4, 2001.

GOLDENBERG, P. \& SCHENKMAN, S. Os egressos em Saúde Coletiva: construindo um perfil. Ciência \& Saúde Coletiva, 2(1/2):91-107, 1997.

GUIMARÃES, J. Pós-graduação e pesquisa. In: CAPES. Discussão sobre a PósGraduação Brasileira. Brasília: Editora UnB, 1996. p.31-45.

GUIMARÃES, J. A pesquisa médica e biomédica no Brasil: comparações entre o desempenho científico brasileiro e mundial. Ciência \& Saúde Coletiva, 9(2):303-328, abr.-jun.2004.

GUIMARÃES, R. Bases para uma política nacional de ciência, tecnologia e inovação em saúde. Ciência \& Saúde Coletiva, 9(2):375-388, abr.-jun.2004.

GUIMARÃES, R.; LOURENÇO, R. \& COSAC, R. A pesquisa epidemiológica no Brasil. Série Estudos em Saúde Coletiva, 216, 2002.

KRIEGER, E. M. Avaliando a avaliação da Capes. In: CAPES. Discussão da PósGraduação Brasileira. Brasília: Editora UnB, 1996. p.40-52.

LUZ, M. T. A produção científica em Saúde Coletiva (1994-1995). Ciência \& Saúde Coletiva, 2(1/2):117-141, 1997.

MAGALDI, C. \& CORDEIRO, H. Estado Atual do Ensino e da Pesquisa em Saúde Coletiva no Brasil. Rio de Janeiro: Abrasco, 1983. (Coleção Ensino de Saúde Pública, Medicina Preventiva e Social no Brasil)

MARSIGLIA, R. \& ROSSI, S. S. Caracterização do Ensino, Pesquisa e Recursos Docentes da Área de Ciências Sociais e Saúde nos Cursos de Pós-Graduação em Saúde Coletiva no Brasil. Rio de Janeiro: Abrasco, 1983. (Coleção Ensino de Saúde Pública, Medicina Preventiva e Social no Brasil)

MINAYO, M. C. S. Pós-Graduação em Saúde Coletiva: um projeto em construção. Ciência \& Saúde Coletiva, 2(1/2):53-71, 1997.

MINAYO, M. C. S. \& COSTA, P. Os rumos e desafios: encerrando um processo de avaliação da pós-graduação stricto sensu em Saúde Coletiva (1994-1997). Ciência \& Saúde Coletiva, 3(1):83-93, 1998.

NUNES, E. D. Sobre a Sociologia da Saúde. São Paulo: Hucitec, 1999.

NUNES, E. D. \& COSTA, P. S. Os cursos de Saúde Coletiva - mestrado e doutorado: um estudo sobre as disciplinas básicas. Ciência \& Saúde Coletiva, 2(1/2):7290, 1997.

TANAKA, A. C. A. Perfil da demanda aos cursos de pós-graduação em 1996, na área de Saúde Coletiva. Ciência \& Saúde Coletiva, 2(1/2):108-116, 1997. 
TEMPORÃO, J. C. \& RIVERA, J. U. Caracterização do Ensino e dos Docentes de Administração e Planejamento em Saúde no Brasil. Rio de Janeiro: Abrasco, 1983. (Coleção Ensino de Saúde Pública, Medicina Preventiva e Social no Brasil)

VIACAVA, F. \& LEITÃO, C. Difusão da produção científica dos cursos de pósgraduação em Saúde Coletiva. Ciência \& Saúde Coletiva, 2(1/2):142-153, 1997.

\section{PROJETO INTEGRADO DE AVALIAÇAO DA PÓS-GRADUAÇAO}

Já foi encaminhado ao CNPq, à CAPES, à FINEP e à OPAS (para o Ministério da Saúde estamos aguardando a nomeação do coordenador de C\&T), o projeto integrado de Avaliação da Pós-Graduação Stricto Sensu em Saúde Coletiva no Brasil.

Gestada no IV Congresso de Saúde Coletiva em Recife, esta proposta reúne coordenadores de Pós-Graduação e um número expressivo de pesquisadores frente a um objetivo central:

- avaliar a dinâmica, a trajetória e a produção de conhecimento na área e estabelecer critérios e indicadores sensíveis dos resultados para o ensino, a pesquisa e os serviços.

Contempla os seguintes subprojetos e está sob a coordenação dos citados pesquisadores:

1. A Trajetória da Pós-Graduação em Saúde Coletiva no Brasil - Jairnilson Paim (ISC/UFBA), Juan Stuardo Yazle Rocha (DMS/FM Rib.Preto/USP), Maria Cecilia Puntel de Almeida (DEMISP/Esc. Enfermagem Ribeirão Preto/USP);

2. A Clientela da Pós-Graduação em Saúde Coletiva - Ana Cristina Tanaka (FSP/USP), Celma Martins Guimarães (Escola Enfermagem/UFGO) e Semiramis Melani Rocha (Escola Enfermagem RP/USP);

3. A Inserção dos Egressos de Pós-Graduação em Saúde Coletiva no Mercado de Trabalho - Mara de Andrade Gomes, Paulete Goldemberg, Regina C.R. Stella e Samuel Goihman (EPM);

4. Avaliação e Tendências da Produção Científica em Saúde Coletiva: dissertação e teses - Everardo D. Nunes (DMPS/FCM/UNICAMP) e Maria Helena P. Oliveira (ESC. Enfermagem RP/USP);

5. Avaliação e Tendências da Producão Científica em Saúde Coletiva: divulgação e difusão - Moisés Goldbaum (DMP/FM/USP) e Rita de Cassia B. Barata (DMS/FCM/Sta. Casa SP);

6. A Estrutura Curricular é o Projeto Acadêmico dos Cursos de Pós-Graduação em Saúde Coletiva - Cristina de A. Possas (ENSP/FIOCRUZ) e Maria Élide Bortoletto (CICT/FIOCRUZ);

7. 0 Componente Pedagógico dos Cursos de Pós-Graduação em Saúde Coeltiva - Fernando Lefèvre (FSP/USP) e Miriam Struchiner (NUTES/UFRJ);

8. Avaliação e Perspectivas dos Mecanismos de Intercâmbio entre os Cursos de Pós-Graduação em Saúde Coletiva Ana Maria Canesqui (DMPS/FCM/UNICAMP);

9. Consolidação da Avaliação dos Cursos de Pós-Graduação a Partir do Sistema EXECAPES - Amélia Cohn (DMP/FM/USP) e Francisco Viacava (CICT/FIOCRUZ);

10. Necessidades Técnicas e Operacionais dos Serviços de Saúde e a Pós-Graduação em Saúde Coletiva - Carlo Zanetti, Flávio Goulart e Luiza de Paiva Silva (NESP/UnB);

O projeto integrado está sob a coordenação geral de Maria Cecilia de Souza Minayo e Péricles Silveira da Costa (Abrasco). Previsto para ser realizado e concluído em dois anos, a partir de seu financiamento, este trabalho que tem como meta formular bases e diretrizes para reorientação do campo de ensino e pesquisa na Pós-Graduação em Saúde Coletiva, significa um patamar de maturidade na reflexão sobre nossa área. 


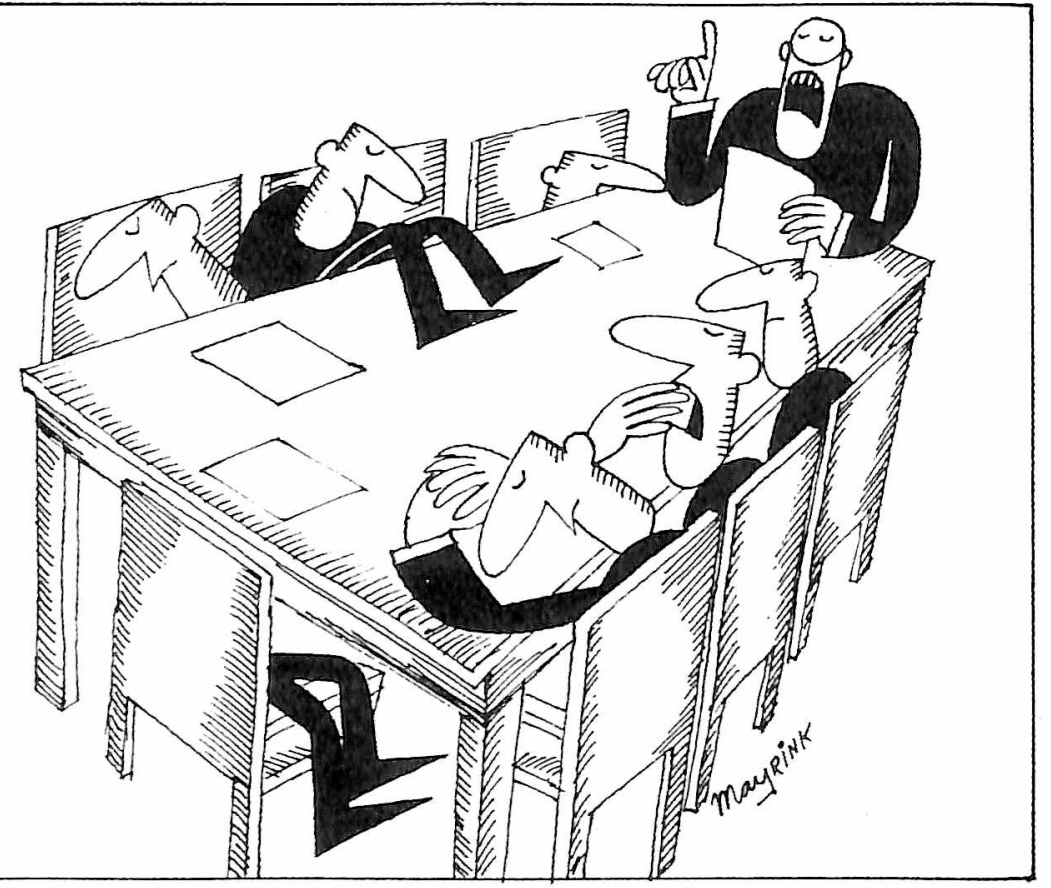

\section{Mestrados e Doutorados pedem maior estímulo ao intercâmbio}

Incrementar o intercâmbio entre os programas, promovendo a qualificação do ensino e da pesquisa, foi a principal recomendação do II Encontro Nacional de Mestrados e Doutorados da Área de Saúde Coletiva. Promovida pela Abrasco, a reunião realizou-se em São Paulo, nos dias 1 e 2 de abril.

O Encontro recomendou ainda a descentralização gradual da pós-graduação em saúde coletiva no pais, a ser desenvolvida em três etapas: implementação dos cursos existentes, através de programação já definida pela Abrasco, a curto prazo: apoio a grupos de pesquisa emergentes em todo o País, principalmente no Norte/Nordeste, através de projetos de assessoria a pesquisadores; e descentralizacão efetiva dos cursos, a longo prazo.

Intercâmbio - Para implementar o intercâmbio entre os programas, os participantes do Encontro propuseram a divulgação, pela Abrasco, da produção cientffica da pós-graduação; a identificação e distribuição de material bibliográfico is existente e periódicos já editados; o elaboração de programa editorial que atenda as necessidades de material bibliográfico (original ou não) entre os cursos.

Recomendou-se ainda a publicação $\theta$ divulgação de catálogo de pós-graduação em Saúde Coletiva no Brasil: implantação de processo ativo de assessoria para pesquisadores: intercâmbio de docentes e sua formalização obtida mediante convênios interinstitucionais de colaboração técrico-cientifica, como os celebrados pela ENSP/USP e IMS/ENSP; a criação da revista da Abrasco, que funcionará como vaículo ideal para produção cientifica da área.

Resolveu-se ainda realizas um encontro, promovido pela Abrasco, reunindo pesquisadores de todo o pais, desde os de grande experiência até aqueles que apenas esbaçam seus projetos de pesquisa. A reuniảo terá como objetivo a definiçâo de linhas prioritárias, de processos de assessoria e o desenvolvimento do esforço organizado em busca de financia- mento à pesquisa para os próximos anos, junto às agências oficiais.

Presentes - Participaram do Encontro repre sentantes da Abrasco, da Secretaria de Recursos Humanos do Ministério da Saúde, da Finep, e dos 10 programas em desenvolvimento no país: Mestrados e Doutorados do Departamento de Medicina da USP (instituição organizadora do eventol. do Departamento de Medicina Preventiva da Faculdade de Medicina de Ribeirão Pretiva da Faculdade de Medicina de Ribeirão Pre-
to: da Faculdade de Saúde Pública da USP; e da Escola Nacional de Saúde Pública e Mestrados do Instituto de Medicina Social da UERJ e da Universidade Federal da Bahia.

A reunião foi aberta pelos prof́s. Cecillia Donnângelo, docente da USP e coordenadora do Enconero: Philadelpho de Siqueira e Paulo Marchiori Buss, respectivamente Presidente $\theta$ Secretário-Executivo da Abrasco.

Na primeira fase do Encontro, os diversos coordenadores presentes discorreram sobre a implantação e desenvolvimento dos respectivos Cursos e sua estrutura atual, curriculos, linhas de pesquisa caraçerização do corpo docente discente, além de analisarem as principais dificuldades enfrentadas.

Debates - Estas breves apresentações foram seguidas de debates, que explicitaram as diferencas metodológicas e de conteúdo entre os diversos programas, curriculos e linhas de pesquisa.

As diferenças entre os projetos foram consi deradas um indicio salutar, por sua característica de pós-graduação senso-estrito e por seus objetivos de formar especialistas, docentes pesquisadores de alto nivel. Recomendouse, porém, a busca constante a em conjunto da explicitarão de campos prioritários para o ensino e pesquisa atendendo os objetivos docentes a compromisso que os Cursos devem ter cam a

Encontra-se em elaboração o relatório final do Encontro, que será oportunamente disiri buido entre todos os interessados. saúde da população brasileira.

\section{MEU FILHO, DE QUE VOCE ESTÁ SOFRENDO?}

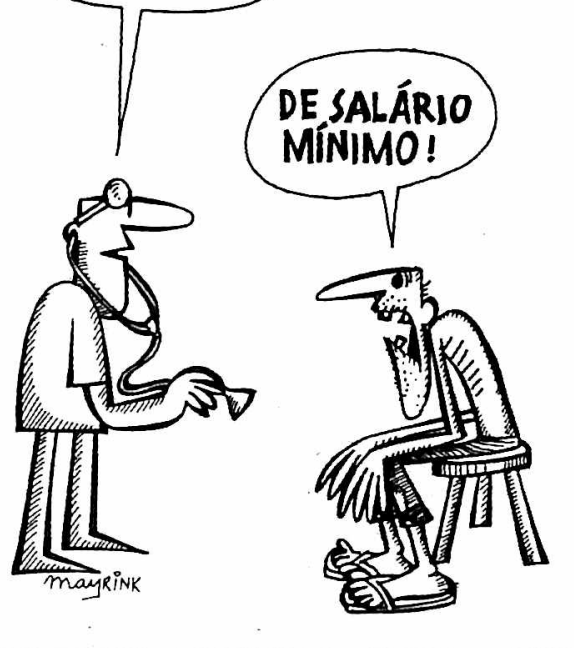

Imagem 13 - Charge de Mayrink. Boletim Abrasco, 18 abr-jun.1986. p.2.

Imagem 14 - Charge de Mayrink. Boletim Abrasco, 2 abr-jun.1982, p.2. 